\title{
UNIDADE OU DIFERENÇA: ENTRE O CORPO DERRIDIANO E A POESIA BLANCHOTIANA ${ }^{1}$
}

\author{
Mayara Joice Dionizio 2 \\ Universidade Federal do Paraná (UFPR) \\ https://orcid.org/0000-0002-8372-9395 \\ E-mail: mayaradioniso@hotmail.com
}

\section{RESUMO:}

O presente artigo explora a divergência interpretativa entre as leituras de Jacques Derrida e Maurice Blanchot a respeito da obra de Antonin Artaud. A obra de Artaud demonstra a problemática acerca do processo da escrita como lugar de ausência, ou seja, a relação decalcada entre o pensamento e sua representação na linguagem falada e escrita. Para Blanchot, a questão sobre o impoder, inerente ao processo da escrita, é experienciada por Artaud como porvir da obra literária/poética, tais quais as obras de outros autores. Nesse sentido, além de fazer de sua obra o lugar de fala sobre o vazio da própria linguagem, Artaud, para Blanchot, também fundamenta sua busca pela totalidade representativa como um problema essencialmente poético. Em contraposição, Derrida aponta que a compreensão blanchotiana de Artaud, a fim de teorizar o ser da escrita, reduz a singularidade e a unicidade da obra artaudiana comparando-a com as obras de outros autores. Nesse contexto, cria-se um paradoxo em relação à obra de Artaud: Derrida afirma a singularidade da obra artaudiana e o teatro como fundamento para uma ressignificação metafísica da linguagem; Blanchot defende que o problema de Artaud é um problema poético/literário, uma vez que a busca por uma expressão total se estende a todos os momentos da obra de artaudiana, inclusive, a teatral.

PALAVRAS-CHAVE: Unidade; Diferença; Neutro; Linguagem; Representação.

\section{UNIT OR DIFFERENCE: BETWEEN THE DERRIDIAN BODY AND BLANCHOTIAN POETRY}

\begin{abstract}
:
The present paper explores the interpretative divergence between the readings of Jacques Derrida and Maurice Blanchot in regards to the work of Antonin Artaud. Artaud's work shows the problematic about the writing proccess as a place of absence, that is, the relationship traced between the thought and it's representation on the spoken and written language. For Blanchot, the question about the impower, inherent to the writing proccess, is experienced by Artaud as the coming of the literary/poetical work, such as the works of other authors. In this sense, besides making your work the speaking place about the emptiness of language itself, Artaud, for Blanchot, also bases his search for the representative totality as a essentially poetic problem. In contrast, Derrida points that Artaud's blanchotian comprehension, in order to theorize the being of writing, reduces the singularity and the oneness of the artaudian work by comparing it with the work of other authors. In this sense, it creates a paradox in regards to Artaud's work: Derrida affirms the singularity of the artaudian work and the theater as the foundation to a metaphysical resignification of language; Blanchot defends that Artaud's problem is a poetical/literary problem, insofar that the search for a total expression extends in every moment of the artaudian work, including, the theatrical.
\end{abstract}

KEYWORDS: Unity; Difference; Neutral; Language; Representation.

\footnotetext{
1 Pesquisa realizada com apoio da Coordenação de Aperfeiçoamento de Pessoal de Nível Superior - Brasil (CAPES) - Código de Financiamento 001

2 Doutoranda em Filosofia na Universidade Federal do Paraná (UFPR), Curitiba - PR, Brasil. Bolsista do(a): Coordenação de Aperfeiçoamento de Pessoal de Nível Superior, CAPES, Brasil.
}

DIONIZIO, Mayara Joice. Unidade ou diferença: entre o corpo derridiano e a poesia blanchotiana. Griot : Revista de Filosofia, Amargosa - BA, v.19, n.2, p.154-170, junho, 2019. 


\section{A exemplificação e o comentário derridiano}

Para Derrida, o essencialismo presente na crítica literária utiliza casos como os de Artaud e Hölderlin com a seguinte perspectiva: "levar a sério, para a crítica, e fazer caso do sentido ou do valor, é ler a essência no exemplo que cai nos parênteses fenomenológicos" (DERRIDA, 2011, p. 251). Nesse aspecto, pode-se dizer que a crítica faz um "comentário mais respeitador da singularidade de seu tema" (DERRIDA, 2011, p. 251). Assim, Derrida aponta na crítica a mesma neutralização, em relação ao Único, que há no domínio do discurso psicopatológico. Dessa forma, a profundidade da crítica literária diante de obras e de seus autores só busca alcançar os elementos comuns que exemplifiquem a existência de uma essência. Segundo Derrida, a visão essencialista de Blanchot não permite o Único, pois reconhecer uma unidade seria retirar o poeta da posição de intermediário da obra. Por essa via, a aventura de Artaud, para Derrida, foi reduzida a um comentário eidético em Le livre à venir, o que faz jus ao título, pois nessa fase da obra blanchotiana a busca ainda era pela essência da escrita e das experiências que a envolvem.

Nesse sentido, Derrida sublinha que o "erro patético" blanchotiano é fazer de Artaud um caso, no qual Blanchot busca a "decriptagem da verdade essencial" (DERRIDA, 2011, p. 251). Esse erro, para Derrida, está na interpretação que Blanchot fez da história de Artaud à procura dessa verdade essencial. O ponto central de reflexão sobre a obra artaudiana, para Derrida, não é encontrar uma verdade comum em relação à escritura, mas, sim, superá-la, no sentido da falta e tentar supri-la por outra metafísica, que para Artaud se configurava na crueldade. No processo de tentar costurar uma fissura (entre pensamento e palavra), Artaud se deparou com a ausência própria da escrita, no caso, poética, e que Blanchot utilizou para justificar a impessoalidade e universalização da experiência literária. Por isso, a crítica derridiana aos comentários essencialistas de Blanchot denunciam a supressão da singularidade e da unidade de Artaud, cujo fim é provar que a experiência da escrita tem aspectos comuns em diferentes autores, que se dão devido ao caráter de "vir-a-ser" de uma obra.

A crítica de Derrida demonstra um incômodo, não só quanto aos comentários feitos por Blanchot sobre Artaud, em defesa de uma universalidade da experiência poética, mas também a afirmação extrema da ontologia poética blanchotiana, que suprime até mesmo a relevância do discurso clínico. Nesse sentido, Derrida critica também a posição de Foucault (apud DERRIDA, 2011, p. 250) de que a incompatibilidade entre crítica e clínica "não é uma figura abstrata, mas uma relação histórica em que nossa cultura se deve interrogar", assinalando que a história tornou-se imprescindível para a existência do comentário como "decifração de estruturas" (DERRIDA, 2011, p. 250). E se essas estruturas, seja a poética, seja a psicológica, conclamam autonomia de discurso sobre suas impossibilidades, de direito e de fato, produzindo assim comentários, é por estarem estruturadas na diferença e na história. Desse modo, Derrida acredita que a obra de Artaud, ainda que causando diferença - pois, ao fim, trata-se ainda de uma obra - suscita uma metafísica da não diferença, de presença e não presença por uma duplicidade do movimento. A superação da diferença em Artaud, assim, se daria pela metafísica da crueldade.

DIONIZIO, Mayara Joice. Unidade ou diferença: entre o corpo derridiano e a poesia blanchotiana. Griot : Revista 
Mas se, por um lado, Derrida acusa a exemplificação que há na aproximação de Artaud e Hölderlin, talvez ele mesmo não tenha conseguido evitar a tentação a qual Blanchot se rendeu. Ao falar sobre o "estar-de-pé" na poesia, Derrida reconhece como "poetas loucos" (DERRIDA, 2011, p. 270) Nietzsche, Hölderlin e Artaud e, sabendo que essa comparação implica no mesmo erro essencialista que acusa em Blanchot, diz:

Hölderlin: 'Contudo agrada-nos, sob o trovão de Deus / ó Poetas! estar de
pé, com cabeça descoberta, / Agarrar o próprio raio paterno com mãos
limpas, / e levar ao povo em véus / No canto, o dom do céu' (Tel, au jour de
repos, trad. J. Fédier). Nietzsche: '[...] Será preciso dizer que também é
necessário sabe-lo [dançar] com a pena?' (Crépuscule des idoles, trad. G.
Bianquis, p.138). Ou ainda: 'Só os pensamentos que nos ocorrem quando
caminhamos têm valor' (p.93). Poderíamos portanto ser tentados, neste
ponto como em muitos, a abranger estes três poetas loucos, em companhia
de alguns outros, no impulso de um mesmo comentário e na continuidade
de uma única genealogia. Mil outros textos sobre o estar-de-pé e sobre a
dança viriam com efeito encorajar semelhante objetivo. (DERRIDA,
2011, p. 270)

Derrida supõe não ter cometido o mesmo erro contra o único por manter a distinção sobre a metáfora entre Nietzsche, Hölderlin e Artaud. A saída, ou mesmo, a convicção derridiana de preservação do único se ampara na "decisão essencial de Artaud" (DERRIDA, 2011, p. 271) em detrimento de Nietzsche e Hölderlin. Derrida assegura a singularidade artaudiana na restituição do roubo pela destruição da metáfora, o estar-de-pé na obra, e Deus como primeiro ladrão: "por esta recusa da estância metafórica na obra e, apesar das semelhanças flagrantes (aqui apesar desta passagem para além do homem e de Deus), Artaud não se filia a Nietzsche. Ainda menos a Hölderlin" (DERRIDA, 2011, p. 272). Essa restituição sobre a diferença metafísica e o corpo se daria pelo teatro.

É precisamente nessa passagem que Derrida aponta para o erro, ainda mais essencialista, da leitura e da compreensão de Blanchot sobre a obra de Artaud. Se destruir a metáfora é o essencial para se restituir o corpo, isso se dá pela superação da poesia que é essencialmente metafórica e ladra. Então, segundo Derrida, Blanchot fez uma leitura equivocada ou deliberadamente ignorou a totalidade do teatro para Artaud ao sugerir que a poesia era o objetivo do teatro da crueldade. Curiosamente, essa importante afirmação de Derrida consta em nota ${ }^{3}$ e se trata de um argumento importante para o que é evocado pela obra artaudiana, mas que, na verdade, é um problema filosófico que a extrapola: a questão sobre o poder da representação.

É por isso que a poesia enquanto tal permanece aos olhos de Artaud uma arte abstrata, que se trate de palavra ou de escritura poéticas. Só o teatro é arte total e que se produz, além da poesia, da música e da dança o

\footnotetext{
3 "La Cruelle raison poétique" foi publicado originalmente pela Cahiers de la compagnie Madeleine Renaud-Jean Louis Barrault, em maio de 1958 ( pp 66-73). Posteriormente republicado pela Gallimard, em 1969, junto a outros ensaios de Blanchot contidos na obra L'entretien infini sob o título "La Cruelle raison poétique: rapace besoin d'envol". Tal informação é relevante, pois mesmo que a publicação mais conhecida de "La Cruelle raison poétique" seja de 1969, Derrida publicou o ensaio "La parole soufflê" presente em L'écriture et la différence em 1967. Ou seja, a leitura do ensaio de Blanchot, por parte de Derrida, ocorreu antes da compilação dos ensaios em livro.
}

DIONIZIO, Mayara Joice. Unidade ou diferença: entre o corpo derridiano e a poesia blanchotiana. Griot : Revista de Filosofia, Amargosa - BA, v.19, n.2, p.154-170, junho, 2019. 
aparecimento do próprio corpo. Assim perdemos o nervo central do pensamento de Artaud quando vemos nele em primeiro lugar um poeta. Exceto evidentemente se fizermos da poesia um gênero ilimitado, isto é o teatro como seu espaço real. Até que ponto poderemos seguir Blanchot quando escreve: 'Artaud deixou-nos uma Arte poética. Reconheço que fala nela do teatro, mas o que está em causa é a exigência da poesia tal como pode realizar-se recusando apenas os gêneros limitados e afirmando uma linguagem mais original... já não se trata então apenas do espaço real que a cena nos apresenta, mas de um outro espaço...'? Até que ponto temos o direito de acrescentar entre aspas "da poesia" quando citamos uma frase de Artaud definindo "a mais alta ideia do teatro"? (Cf. La Cruelle raison poétique, p. 69) (DERRIDA, 2011, p. 273).

Adiante, ao falar da reintrodução da palavra no teatro, ainda que submetida à escritura teatral, Derrida reconhece que, ao querer extinguir a obra, Artaud é também o autor de uma, inclusive a reintroduzindo em sua teoria teatral. Da mesma forma, Derrida se demonstra consciente de ter feito um comentário e reconhece, também em nota, que repetiu o gesto que criticara em Blanchot. Ainda que, para afirmar uma consciência sobre a "lei cruel da diferença" (DERRIDA, 2011, p. 287), a qual não deve mais ser vivida na ingenuidade metafísica da diferença, mas, sim, na lucidez da diferança, Derrida assume sua incoerência, uma vez que, para refazer o caminho de Artaud e demonstrar como se daria a restituição do corpo e da metafísica, faz uso da mesma exemplificação essencialista e do furto que é o comentário.

\begin{abstract}
Artaud não reintroduziu apenas a obra escrita em sua teoria do teatro; é também, afinal de contas, o autor de uma obra. E sabe disto. Numa carta de 1946 (citada por Blanchot em L'Arche, 27-28,1948, p.133), fala desses "dois livros muito pequenos" (L'Ombilic e Le Pèse-nerfs) que "rolam sobre essa ausência profunda, inveterada, endêmica de toda ideia". "No momento pareceram-me cheios de rachas, de falhas, de mediocridades e como recheados de abortos espontâneos... Mas vinte anos mais tarde parecem-me espantosos, não de sucesso em relação a mim, mas em relação ao inexprimível. É assim que as obras ganham sabor e que, mentindo todas em relação ao escritor, constituem por si próprias uma verdade bizarra...Um inexprimível expresso por obras que não passam de destroços presentes...' Então, pesando na recusa crispada da obra, não se pode dizer com a mesma entonação o contrário do que diz Blanchot em Le Livre à venir? Não: "naturalmente, não é uma obra" (p.49), mas: "naturalmente, não passa ainda de uma obra"? Nesta medida, autoriza a efração do comentário e da violência da exemplificação, aquela mesma que não pudemos evitar, no momento em que pretendíamos defender-nos dela. Mas talvez compreendamos melhor agora a necessidade desta incoerência. (DERRIDA, 2011, p. 286, grifo meu)
\end{abstract}

É este o argumento de Derrida: se Artaud, ao produzir uma obra, ainda que para acabar com a possibilidade de obra, ou lançar luz sobre o que é uma obra, autoriza o roubo, mesmo com a consciência do roubo, o faz com o objetivo de comunicar sobre a estrutura do furto, que é a linguagem, ainda que a utilizasse. Fica claro que Derrida sabia o caminho de sua crítica, que implicaria na mesma 
ingenuidade 4 que acusa no início de "La parole soufflé". E, a partir dessa incoerência, como não reconhecer em Derrida um essencialismo, uma exemplificação? Ainda que os objetivos sejam distintos dos de Blanchot, no caso de Derrida, construir um caminho para diminuir as ingenuidades entre discursos, sobre a diferença, uma possível ressignificação metafísica, que como nos disse Artaud: "fazer a metafísica da linguagem articulada é fazer com que a linguagem sirva pra expressar aquilo que habitualmente ela não expressa: é usá-la de um modo novo, excepcional e incomum, é devolver-lhe suas possibilidades de comoção física" (ARTAUD, 2006, p. 46). Ou seja, é reintroduzindo, renovando a linguagem através do corpo e abrindo-a ao devir em que se diminui a dicotomia, ou que se criam novos modos de tentar diminuí-la. Nesse sentido, da aventura de uma renovação da metafísica, Derrida reconhece em Artaud uma unidade, a qual se pode encontrar não uma essência poética, ou uma experiência predominantemente poética, mas na poesia enquanto transcendência (impossibilidade de direito) que, combinada com a estrutura esquizofrênica (impossibilidade de fato), realiza o Único.

Assim explica Derrida (2011, p. 287): “o que liga o conceito da loucura ao conceito de metafísica em geral: a que Artaud destrói e a que se empenha ainda em construir ou em preservar no mesmo movimento". Ou seja, o discurso de conjunção entre loucura e obra que resulta o Único está amparado em uma metafísica que busca não diferir. De outro modo, Derrida conclui que não se trata de entender Hölderlin por um dos discursos - esquizofrênico ou transcendental - mas sim de "ler e ver desenhar-se em Hölderlin um acesso, talvez o melhor, um acesso exemplar à essência da esquizofrenia em geral" (DERRIDA, 2011, p. 287). Com isso, compreende-se a loucura como uma estrutura que traz possibilidades de acesso do homem à sua verdade humana. Assim, para Derrida, é possível reconhecer em Artaud e Hölderlin um acesso único singular, atravessado pela esquizofrenia como um horizonte de sentido para suas obras.

Derrida, ao fim de "La parole soufflé", justifica seu movimento duplo em relação ao seu furto, ao comentário que fez de Artaud. Para Derrida, a leitura de Artaud acompanha o limite proposto pela obra artaudiana e, por isso, a mesma duplicidade que essa obra apresenta. Se Derrida se expõe a um essencialismo sabendo-o, sua defesa são os rastros de Artaud em direção à diferança que é inacessível se não for por um duplo: a metafísica que é questionada é a que permite questionar. Ou, de outro modo, a obra e o comentário são necessários para uma crítica à própria essência da obra e do comentário.

Nesse sentido, a duplicidade é a diferença que permite reconhecer a diferença ainda estando nela, praticando-a. Aqui, Derrida se refere ao duplo enquanto a alétheia heideggeriana: "abrindo e ao mesmo tempo recobrindo a verdade, nada distinguindo de fato, cúmplice invisível de toda a palavra, é o próprio poder furtivo" (DERRIDA, 2011, p. 287). É possível, então, identificar em Derrida uma interpretação da presença pertinente à verdade em que a linguagem é a possibilidade de apreensão; é esse ponto de interesse pelo que insinua a obra de Artaud. Desse modo, a escritura se torna um problema a partir do que pretende representar: a

\footnotetext{
4 "Ingenuidade do discurso que aqui iniciamos, falando em direção de Antonin Artaud. Para reduzi-la teria sido necessário esperar muito tempo: que na verdade fosse aberto um diálogo entre - digamos, para sermos breves, o discurso crítico e o discurso clínico" (DERRIDA, 2011, p. 249).
} 
captação imediata de uma presença. E, a partir dessa possível constatação, Derrida propõe, através de uma "cumplicidade fatal" da duplicidade metafísica, "a inserção necessária de todos os discursos destruidores, que devem habitar as estruturas por eles derrubadas e nelas abrigar um desejo indestrutível de presença plena, de nãodiferença: ao mesmo tempo vida e morte" (DERRIDA, 2011, p. 288). Para Derrida, seria esse o caminho, seguindo os rastros de Artaud, utilizando a diferença em um movimento contra ela mesma, dado pela duplicidade metafísica em que se daria a transgressão da diferença nela mesma.

\section{A diferença insuperável: o desconhecido, o neutro}

É possível estabelecer uma problematização em torno de uma comparação de conceitos e estruturas de pensamento entre Derrida e Blanchot. Encontra-se nas obras de Derrida e Blanchot uma distinção central nos modos de compreensão e teorização, não só em relação à escritura, mas também a respeito da ontologia e da metafísica em geral. Enquanto Derrida defende o Único singular do perigo de uma diferença, acusando o diferimento blanchotiano, Blanchot, em sua interpretação ontológica e fenomenológica, acredita que é impossível não diferir. Se Blanchot comete um reducionismo clínico referente ao caso de Artaud ao dizer que "não se deve cometer o erro de ler como análises de um estado psicológico as descrições precisas, seguras e minuciosas que ele nos propõe" por se tratarem de "descrições [...] de um combate" (BLANCHOT, 2013. p. 54), é por acreditar que a interpretação psicopatológica tende a defender que a obra, nesses casos, é causada ou atravessada pela doença mental. Blanchot acredita, como aponta Derrida, que o discurso clínico, no caso de Artaud e Hölderlin, amparou a experiência poética/literária em um estado psicológico no qual justifica a obra de ambos. Ou mesmo, quando falam de Hölderlin, que o "aparecimento" de um quadro psicótico é o que permitiu o surgimento dos hinos. Blanchot reconhece, sim, o argumento psicológico, mas não acha que este seja fundante de uma experiência artística nesses casos; Hölderlin e Artaud foram arrebatados por necessidades e preocupações tão pertinentes ao processo de escrita que é difícil interpretá-las como sintomas de uma doença. Por outro lado, Blanchot compara Hölderlin a Artaud sobre uma mesma experiência de criação poética, não somente a fim de refutar o argumento clínico, mas também de reconhecer em ambos uma extrema submissão ao vir-a-ser da palavra quando relacionado à poesia.

Nesse sentido, é necessário, para além da leitura de Blanchot sobre Artaud e Hölderlin, mas ainda os tendo como centro de gravidade, explicitar os conceitos e o pensamento de Blanchot sobre poesia, diferença e ontologia, a fim de pontuar sua posição em relação às críticas de Derrida. O pensamento de Blanchot acerca de uma ontologia da poesia muda ao longo de sua obra, se em um primeiro momento, como em Le livre à venir, podemos encontrar uma busca mais acentuada por uma essência e nisso encontra-se o primeiro comentário sobre Artaud. Já o segundo comentário sobre Artaud, "La cruelle raison poétique", está reunido junto a outros ensaios que expressam a relação da escrita com o desconhecido, com o neutro. Na obra de Blanchot, a linguagem literária é uma forma de conceber a linguagem, uma espécie de âmbito de permissão para além de sua verdade e sentido. Uma presença anterior

DIONIZIO, Mayara Joice. Unidade ou diferença: entre o corpo derridiano e a poesia blanchotiana. Griot : Revista de Filosofia, Amargosa - BA, v.19, n.2, p.154-170, junho, 2019. 
que nunca se confirma e que só a percebemos e a sabemos pela ausência, pela sensação de perda que ocorre na escrita. Assim, mais do que buscar uma essência, Blanchot passa a escrever sobre a grande ausência que constitui a escrita e que só se torna possível por esse fundo precedente, por esse desconhecido. Os termos que a explicam são "mistério", "fora", "impossibilidade", "anônimo" e "neutro". E se, ao longo de sua obra, Blanchot abandona uma ontologia, é por perceber que a essência é incapturável e, se assim o é, a escrita trata muito mais de um desconhecido que a precede do que de uma presença que se confirma - presença que, inclusive, sem esse precedente, não existiria. No entanto, os dois comentários, mesmo que escritos em momentos distintos do pensamento de Blanchot sobre a escrita e a ontologia, são objetos de análise de Derrida.

O primeiro comentário sobre Artaud e que consta em Le livre à venir relata justamente o vazio que a obra artaudiana exalta. Nesse aspecto, entendo que a gravidade do que foi evocado por Artaud, a supressão da diferença entre palavra e pensamento, sinaliza para Blanchot justamente a diferença irreversível, insuperável entre pensamento e representação, e isso é, no caso de Artaud e Hölderlin, uma questão de poesia. Se a ênfase do entendimento derridiano é, juntamente com Artaud, não diferir, e isso implica em reconhecer na obra artaudiana não uma arte poética, mas sim uma arte teatral, é porque no teatro o corpo tem a máxima restituição de suas diferenças: corpo com órgãos, fezes/obra, pensamento e palavra. Mas em Blanchot tem-se o contrário. Diferentemente de Derrida, que já no sentido de seu entendimento sobre Artaud atenta-se em não roubá-lo e vê nessa forma de lêlo a única maneira de preservar sua unidade, Blanchot já percebe nos relatos artaudianos a descrição precisa do que é a diferença quando atrelada à poesia. Ou seja, é o deslocamento da escrita de Artaud, que foi conduzido por Jacques Rivière em um primeiro momento, em que não se tenta mais escrever poesia pela poesia, mas sim em se expor à poesia para poder relatar a impotência de escrevê-la, de efetivá-la. Desse modo, Blanchot reconhece nas cartas com Rivière, em L'ombilic des limbes e Le pèse-nerfs, a descrição de uma exigência dolorosa, que configura a obra de Artaud como uma arte poética, não pela realização da poesia, que não acontece, mas pela busca de restauro de si que é a esperança poética de toda sua obra.

Na fase teatral de Artaud, na obra Le théâtre et son double, por exemplo, pode-se encontrar em diversos capítulos sentenças como estas: "essa linguagem que evoca ao espírito imagens de uma poesia natural (ou espiritual) intensa dá bem a ideia do que poderia ser no teatro uma poesia no espaço independente da linguagem articulada" (ARTAUD, 2006, p. 39) e "seja o que for essa linguagem e sua poesia" (ARTAUD, 2006, p. 39), ainda "tudo neste modo poético e ativo de considerar a expressão em cena" (ARTAUD, 2006, p. 47). Blanchot não ignora o teatro, mas considera que a finalidade do teatro é uma expressão poética em Artaud. Assim, a restituição do pensamento na poesia e a restituição do corpo no teatro significam um movimento em relação à poesia e, nesse sentido, para Blanchot, a obsessão de Artaud por uma expressão que só a poesia poderia proporcionar faz com que toda obra artaudiana seja fixada sobre o relato dessa impossibilidade. Se Artaud acreditava superar de alguma forma o desnível entre pensar e escrever, e todas as outras dicotomias que estão presentes em sua obra, para Blanchot, o que interessa na obra de Artaud é que ela se constituiu sobre o que é essa diferença. Daí a querela entre os

DIONIZIO, Mayara Joice. Unidade ou diferença: entre o corpo derridiano e a poesia blanchotiana. Griot : Revista de Filosofia, Amargosa - BA, v.19, n.2, p.154-170, junho, 2019. 
dois autores: Derrida lê Artaud talvez como Artaud gostaria de ser lido e busca uma forma de não diferença (teatro); Blanchot lê Artaud como testemunho da diferença (poesia) e, desse modo, o aproxima de outros que também relataram a falta que compõe o processo de escrita, como Hölderlin, Sade, Mallarmé, Rilke. Sobre a diferença que é a poesia, relata-nos Artaud (2006, p. 76):

\begin{abstract}
A expressão verdadeira esconde o que ela manifesta. Opõe o espírito ao vazio real da natureza, criando por reação uma espécie de cheia no pensamento. Ou, se preferirem, em relação à manifestação-ilusão da natureza ela cria um vazio no pensamento. Todo sentimento forte provoca em nós a ideia de vazio. E a linguagem clara que impede esse vazio impede também que poesia apareça no pensamento. É por isso que uma imagem, uma alegoria, uma figura que mascare o que gostaria de revelar têm mais significação para o espírito do que as clarezas proporcionadas pelas análises da palavra.
\end{abstract}

Assim, pode-se então falar sobre a ontologia que é a base da poesia para Blanchot nesse primeiro comentário de Artaud. A poesia é diferença porque sua tarefa consiste em expressar, representar um fundo, uma essência, o ser da poesia. Nesse sentido, a experiência de Artaud cumpre o processo poético que é a relação com o imediato: o pensamento que escapa, que não se completa quando está prestes a existir poeticamente. É esse imediato, a que só se expõe quem tenta o ato da escrita poética, em que consiste o ser da poesia, portanto, incapturável: "um ser e, por isso mesmo, de forma nenhuma mais próximo do ser, do que escapa a toda determinação e a toda forma de existência" (BLANCHOT, 2011b, p. 37).

Por isso, não se pode dizer que o poema pertença ao ser da poesia; o que se pode dizer é que a poesia não existe ao modo geral de um ente. Assim, o poema é provocado por uma essência da poesia, mas quando se torna obra, "presença que, por sua vez, retorna à ausência pelo movimento de erosão" (BLANCHOT, 2011b, p. 37), uma vez que, um poema é aberto, é duplo: se realiza como obra, mas também se mostra inapreensível. Desse modo, a busca de Artaud por uma linguagem que expressa seu pensamento poético delineia-se, mesmo na fase teatral e pictográfica, como um problema de representação essencialmente poético.

Em L'espace littéraire, ao falar de "A experiência de Mallarmé", Blanchot define a poesia em relação com a morte, ausência e irrealidade a partir do ser, ou mesmo do "é". Para Mallarmé, esse centro que precede a escrita e que a ultrapassa é onde se encontra todo o mistério. $O$ que permite a Blanchot pensar a existência da poesia/literatura como algo que não existe como as outras coisas, porque "da ausência de tempo onde nada se conclui, é elevada à afirmação única, fulminante do começo" (BLANCHOT, 2011b, p. 36). Se a poesia/literatura não existe como um objeto, o que existe, apesar de estar escrita em uma linguagem, é o resultado de uma atividade humana que se preserva aberta ao todo e ao nada. Ou seja: um poema, um livro, pode conter uma totalidade de sentido em relação à existência, assim como pode não fazer sentido algum para quem o lê. $O$ que configura tanto para Blanchot quanto para Mallarmé e, certamente, para Artaud, que essa passagem do tudo ao nada é essencial, portanto, é o instante de essência da linguagem, do mistério, do nada trabalhando na escrita. Dessa forma, pode-se entender a autonomia da linguagem no mundo.

DIONIZIO, Mayara Joice. Unidade ou diferença: entre o corpo derridiano e a poesia blanchotiana. Griot : Revista de Filosofia, Amargosa - BA, v.19, n.2, p.154-170, junho, 2019. 
Mas, tendo esse poder de fazer as coisas "erguerem-se" no seio de sua ausência, senhoras dessa ausência, as palavras também têm o poder de se dissiparem a si mesmas, de se tornarem maravilhosamente ausentes no seio de tudo que realizam, de tudo que proclamam anulando-se, do que eternamente executam destruindo-se, ato de autodestruição sem fim, em tudo semelhante ao suicídio (BLANCHOT, 2011b, p. 37).

Blanchot acredita que Artaud foi vítima do imediato e do risco da experiência literária, situação que o expôs ao jugo do discurso clínico. O ponto central ao qual Artaud se expunha constantemente é o da ambiguidade central, o momento em que a realização da poesia é também o desaparecimento da poesia, pois a palavra já resta como lembrança, aparência do que desapareceu. Para Blanchot, esse imediato incapturável, incessante e interminável é o que incita a escrita e não se deixa representar; nessa relação, quem escreve se deixa dominar por esse instante e em uma obsessão persegue esse momento, o que acaba por se tornar a obra. Ou seja, a origem da obra não é o escritor, mas sim a ausência de obra; o escritor se torna mero intermediário. Nesse sentido, Blanchot assume, posteriormente, esse mistério da linguagem, da escrita, de tudo ao nada, dentro do que ele chama de "neutro". Noção pensada a partir, e conjuntamente, de Levinas, e que consiste em pensar o "il y a", no qual, mesmo reconhecendo na filosofia heideggeriana a diferença ontológica entre ser e ente, o neutro é o que permite pensar o anônimo do ser num sentido impessoal do ser, que o precede e que sucede todo ser. Desse modo, um rumor anônimo anterior e posterior a toda verdade e sentido (CARVALHO, 2007).

Assim, ao falar do neutro, Blanchot está buscando reconhecer uma experiência com o desconhecido, porém determinante. O "neutro" para Blanchot está sempre associado à experiência com o desconhecido. Trata-se de algo que não se pode deter, nem o sujeito e nem o objeto, e que também não pode ser classificado em nenhuma dessas categorias; no entanto, não é um indeterminado prestes a ser determinado, não tem gênero: “o neutro é aquilo que não se distribui em nenhum gênero: o não geral, o não genérico, assim como o não particular" (BLANCHOT, 2010b, p. 30). Para Blanchot em toda relação com o desconhecido está sempre implícita a experiência com neutro ${ }^{5}$. Se relacionar-se com o desconhecido é, dessa

\footnotetext{
5 A concepção blanchotiana de neutro, pensada a partir de uma meta-ontologia e engajada sobre a atividade literária, não se difere da concepção de neutro levinasiana. Em Totalité et infini, Levinas contesta o modo como a filosofia fundamentou a ontologia a partir da ideia do Mesmo: "para a tradição filosófica Ocidente, toda a relação entre o Mesmo e o Outro, quando deixa de ser a afirmação da supremacia do Mesmo, se reduz a uma relação impessoal numa ordem universal. A própria filosofia identifica-se com a substituição das pessoas pelas ideias, do interlocutor pelo tema, da exterioridade da interpelação pela interioridade da relação lógica. Os entes reduzem-se ao Neutro da ideia, do ser, do conceito" (LÉVINAS, 1980, p. 74). Nesse sentido, é a partir da percepção de uma alteridade, ou seja, de pensar o Outro como outrem e não como um Mesmo de mim, que permite o Neutro. Blanchot ressalta em L'entretien infini que: "para Heidegger o ser-com é apenas abordado em relação com o Ser porque, à sua maneira, sustenta a questão do Ser. Para Hurssel, se não me engano, apenas a esfera do ego é original, a de outrem é para mim somente 'apresentada'. De uma maneira geral, quase todas as filosofias ocidentais são filosofias do Mesmo e quando elas se preocupam com o Outro, este não passa de um outro eu mesmo, sendo, no melhor dos casos, igual ao eu e procurando ser reconhecido por mim como Eu (assim como eu por ele), numa luta que por vezes é luta violenta, por vezes violência apaziguada no discurso. Mas, somos conduzidos pelo ensino de Levinas em direção a uma experiência radical. Outrem é irredutivelmente Outro; o outro é o que me ultrapassa absolutamente.[…] Acontece que ele é justamente o Estrangeiro. Supúnhamos, no início, que relação com este Desconhecido era a própria filosofia: Levinas diz, a metafísica. O Estrangeiro vem de outro lugar e nunca está onde estamos, não pertence ao nosso horizonte e não aparece em nenhum horizonte
}

DIONIZIO, Mayara Joice. Unidade ou diferença: entre o corpo derridiano e a poesia blanchotiana. Griot : Revista de Filosofia, Amargosa - BA, v.19, n.2, p.154-170, junho, 2019. 
forma, dar abertura para o espaço em que me relaciono com o neutro, é porque se trata do outro inapreensível, da estranheza em relação ao que se difere de mim: é a diferença absoluta. Assim, o neutro é sempre em relação ao outro. Blanchot reconhece que Heráclito foi um dos primeiros na história do pensamento filosófico ocidental a falar do neutro: “O um-a-coisa-sábia', 'o não-de-esperar', 'o-não-deencontrar" (BLANCHOT, 2010b, p. 30). Nesse sentido, a fala de Heráclito, segundo Blanchot, não se determina como conceitos aristotélicos ou hegelianos e, ainda menos, partindo de Platão, poderia se enquadrar como ideias. A fala de Heráclito é neutra. Desse modo, Blanchot defende que há na história da filosofia um empenho em dominar, domesticar e esquivar o pensamento sobre o neutro por nele haver a própria impossibilidade de conhecimento.

Se podemos falar sobre uma recusa do neutro na reflexão ocidental, Blanchot evidencia que, da perspectiva do conhecimento, da relação entre sujeito e objeto, o neutro foi substituído pela impessoalidade ou pela universalidade; assim, afirmou-se sobre o neutro ora "a primazia ética do Eu-Sujeito", ora "a aspiração mística do Único singular" (BLANCHOT, 2010b, p. 31), do mesmo modo que Derrida afirma um único em prol de uma metafísica. Ou seja, para Blanchot, a experiência como neutra pressupõe uma estranheza a qualquer relação de identidade, unidade e de presença. $\mathrm{O}$ desconhecido, ao contrário do movimento de desvelamento em que se ilumina, suspende a presença, é manifesto em relação à escrita como desconhecido. Desse modo, a poesia se relaciona com o desconhecido "por uma descoberta que o mantém encoberto" (BLANCHOT, 2010b, p. 32); assim, há presença desse desconhecido, mas como tal. Portanto, se essa relação não pressupõe um desvelamento, dessa relação não se pode fundar um conhecimento: o desconhecido não pertence à luz, ao visível-invisível, nem a presença à iluminação. Isso significa que, para Blanchot, a experiência da poesia enquanto pensamento do neutro não está associada ao negativo e nem ao positivo. Nesse sentido, ausência de luz ou a abertura de luz não determinam a relação neutra da poesia com desconhecido; sendo aquela que escapa a toda apreensão, a poesia dentro dessa experiência neutra se relaciona com o devir sem exercício de poder. Desse modo, a poesia é a escrita do infinito: escrever sem vínculo é escrever em uma submissão ao infinito, do que não se conhece.

Se em "La cruelle raison poétique", Blanchot parte de Artaud para falar do neutro, é no sentido em que se ressignificam os relatos presentes na obra artaudiana. O que antes, em "Artaud" de Le livre à venir, configurava uma relação entre Artaud e o imediato, depois do pensamento do neutro, Blanchot reconhece que se trata de uma relação entre Artaud e o imediato, que é o desconhecido, portanto, o neutro. Ao reconhecer na linguagem o espaço de experiência do neutro, Blanchot repensa a ontologia da escrita. Portanto, Derrida, ao acusar Blanchot de um essencialismo em detrimento ao único, dá ênfase ao comentário "Artaud" de Le livre à venir, mas, ainda assim, cita "La cruelle raison poetique", que trata de outra concepção sobre a escrita. Se no primeiro comentário de Blanchot a busca por uma essência da escrita o leva a comparar vários escritores e suas experiências, em um segundo momento, as comparações entre os autores são em demonstração de uma escrita interrompida,

representável, de forma que o invisível seria o seu 'lugar, entendendo com isto, segundo uma terminologia que às vezes usamos: o que se desvia de todo visível e de todo invisível" (BLANCHOT, 2010a, p.98-99).

DIONIZIO, Mayara Joice. Unidade ou diferença: entre o corpo derridiano e a poesia blanchotiana. Griot : Revista de Filosofia, Amargosa - BA, v.19, n.2, p.154-170, junho, 2019. 
atravessada pelo neutro. Ou seja, Blanchot passa a reunir e escrever sobre obras que se expressam neutras, no sentido de se mostrarem sem reconhecimento de um sujeito, fragmentárias porque são diferença e descontinuidade da escrita.

Ao refutar o primeiro comentário de Blanchot sobre Artaud, Derrida trata apenas do essencialismo, mas não traz essa importante mudança, na qual a experiência artaudiana é repensada. Tratar do segundo comentário de Blanchot seria ter que lidar com dois momentos da obra blanchotiana: a supressão do Único em prol de uma essência da escrita e, em um segundo momento, a diferença afirmada em relação à escrita pela ideia de neutro. Se tratarmos esta segunda fase da obra blanchotiana como a recusa de uma essência, é porque Blanchot percebe que este desconhecido é incapturável e passa a não mais traçar uma relação entre escritor e essência no sentido de uma ontologia, mas sim "como uma rede de relações que não se deixa jamais exprimir unitariamente" (BLANCHOT, 2010b, p. 182). Dessa forma, deve-se pensar a comparação entre Hölderlin e Artaud por outra via: trata-se ainda da manifestação na obra de ambos sobre a impossibilidade que se configura na escrita, mas, depois, tal comparação é a aproximação de dois espaços de diferença que expressam a interrupção na escrita quando atravessada pelo neutro. Artaud e Hölderlin tiveram experiências distintas, plurais, e que, no entanto, comunicaram-se com o desconhecido e "comunicar com o desconhecido exige a pluralidade" (BLANCHOT, 2010b, p.182). Ao reconhecer a experiência com o neutro como plural, Blanchot está reconhecendo, também, a diferença, ou seja, não se trata de excluir as singularidades de Hölderlin e Artaud, mas sim de pensá-las a partir de uma estrutura plural, que, ainda assim, relatam o mesmo problema de representação. Portanto, Blanchot passa a considerar a diferença não só como desnível entre pensamento e representação, mas, também, como uma pluralidade, que é o modo de manifestação do desconhecido. Pode-se, então, acrescentar que Blanchot, nesse segundo momento de sua obra, compara Artaud e Hölderlin dentro de um traço múltiplo em relação à escrita, que é diferença.

Desta feita, não se trata mais de uma busca unificadora. Eu não quero mais reconhecer no outro aquele ou aquilo que uma medida ainda comum, o fato de pertencer a um espaço comum, mantém numa relação de continuidade e ou de unidade comigo. Agora, o que está em jogo, é a estranheza entre nós, e não somente esta parte obscura que escapa a nosso mútuo conhecimento e não é nada mais do que a obscuridade da posição do eu - a singularidade do eu singular - estranheza que é ainda muito relativa (um eu está próximo de um eu, mesmo na diferença, na competição, no desejo e na necessidade) (BLANCHOT, 2010a, p. 133).

Quando Derrida fundamenta sua crítica sobre uma redução essencialista de Artaud e Hölderlin em Blanchot, não está reconhecendo a alteração plural da diferença blanchotiana ou mesmo a alteridade que fundamenta tal aproximação. Derrida, então, refuta Blanchot somente a partir da primeira aproximação entre Hölderlin e Artaud, apontando um essencialismo, ainda que conhecendo essa alteração na obra blanchotiana e sabendo que a segunda comparação, no segundo comentário, implica, justamente, em um não essencialismo, em uma negação da ontologia. Nesse sentido, Blanchot reconhece a pluralidade que há na experiência da escrita, justamente por se tratar de um espaço de forças múltiplas causadas pelo 
desconhecido, mas que, ainda assim, configura-se em uma relação com o outro e com a obscuridade que intervém.

\begin{abstract}
Pode-se concluir sem temor ser este um altíssimo jogo de escrita. Cada frase é um cosmos, um arranjo minuciosamente calculado em que os termos estão em relações extremas de tensão, jamais indiferentes à sua localização ou à sua figura, mas como que dispostos em vista de uma Diferença secreta que tão-somente indicam ao mostrar, a título de medida, as mudanças, as conversões visíveis de que a frase é o lugar separado. Arranjo fechado: cada fórmula é tacitamente suficiente, ela é única, mas em unidade com o silêncio que abre e fecha e que reúne virtualmente a perigosa sequência das alternâncias ainda não dominadas (BLANCHOT, 2007, p. 13).
\end{abstract}

Assim, pode-se, também, pensar a recusa de Blanchot sobre o domínio do duplo em relação à linguagem, do modo como pensou Derrida: diferença sendo superada pela diferança, a não ingenuidade sobre o furto possibilitando certa forma de presença, ou seja, de suspensão. Pois, para Blanchot, trata-se de uma alternância entre o mesmo e o diferente, o eu e o ele, sempre com a intermitência de uma obscuridade. Então Blanchot reconhece a impossibilidade de domínio do duplo, porque o entre-lugar, o desconhecido, o neutro sempre atravessa e nunca se deixa conhecer ou capturar. Já Derrida incide justamente por uma tentativa de dominação do duplo quando propõe a metafísica da diferança. Nesse aspecto, segundo a crítica de Blanchot: delimitar a "obscuridade da linguagem e a clareza das coisas, o domínio do duplo sentido das palavras e o segredo da dispersão das aparências, isto é, talvez, o dis-curso e o discurso" (BLANCHOT, 2007, p. 12). Assim, se para Blanchot pensar dis-curso e o discurso assinalam a interrupção, uma diferença presente na linguagem, para Derrida, a alteração entre diferença e diferança incide em uma tentativa de domínio do duplo, uma vez que tem a finalidade de superar a diferença. Por isso, se Blanchot recusa pensar a escrita como uma captura, como uma presença, mas, sim, como um espaço de ausência - ou seja, eu só escrevo sobre o que me falta - é nesse sentido que assume o outro como exterior insuperável, isto é, a diferença insuperável; pois se existe palavra, é porque a diferença a precede e sucede. Portanto, há suspensão na escrita, pode-se dizer que seria da presença enquanto afirmação de ausência, ou seja, toda escrita está edificada sobre a falta, é sempre o que já não está, sempre o que não sou eu.

Então, para Blanchot, essa busca de transcendência pela atividade poética, e que se pode encontrar tanto nos relatos de falta de Artaud quanto na ressignificação metafísica derridiana, está associada ao desejo metafísico. Em Artaud a poesia é o desejo, é a relação com o impossível. E, em Derrida, o desejo metafísico pela unidade, daquilo que nunca foi unido, do ser inteiro, é o que constitui esse duplo: a necessidade de superação dessa diferença. Dessa forma, pode-se estabelecer e reconhecer o que aproxima Derrida de Artaud, e de que forma o desejo filosófico derridiano entendeu o desejo poético artaudiano. Para Blanchot, o desejo filosófico/poético é herança do Eros platônico ${ }^{6}$ no aspecto de nostalgia pela unidade

6 “[quem deseja], como qualquer outro que deseja, deseja o que não está à mão nem consigo, o que não tem, o que não é ele próprio e o de que é carente; tais são mais ou menos as coisas de que há desejo e amor" (PLATÃO, 2016, p.109; 200e)

DIONIZIO, Mayara Joice. Unidade ou diferença: entre o corpo derridiano e a poesia blanchotiana. Griot : Revista de Filosofia, Amargosa - BA, v.19, n.2, p.154-170, junho, 2019. 
perdida, mas que, ainda assim, difere-se em seu desejo. No desejo metafísico há a felicidade na separação porque isso que faz o "eu" e, assim, é um desejo de busca pelo desejo, um desejo pelo outro inacessível, o desejo é o impossível. Nesse sentido, segundo Blanchot, essa busca de unidade, é a impossibilidade que se faz relação. Desejo impossível presente tanto em Derrida quanto Artaud:

O desejo que se pode chamar metafísico é desejo daquilo que não nos falta, desejo que não pode ser satisfeito e não deseja unir-se com o desejado: ele deseja aquilo que aquele que deseja não tem necessidade, que não lhe faz falta e que ele não deseja atingir, sendo o próprio desejo do que deve permanecer-lhe inacessível e exterior - desejo do outro enquanto outro, desejo austero, desinteressado, sem satisfação, sem nostalgia, sem retorno (BLANCHOT, 2010a, p. 100)

Então, por essa via, a escrita para Blanchot é a impossibilidade de captação do outro. Portanto, quando René Char diz: "o poema é o amor realizado do desejo que permaneceu desejo" (CHAR apud BLANCHOT, 2010a, p.101), Blanchot conclui que o desejo quando relacionado à escrita é desejo de transcendência onde o inapreensível, o outro, é a possibilidade de transcender e que nunca se realiza, pois se trata de capturar o que não sou eu, mas o que é estrangeiro, por isso, não há como teorizar a essência da escrita. Para Blanchot, a escrita passa a ser a presença do outro concebido e interpelado pelo neutro. E, por essa presença neutra, há nas relações a diferença que é o hiato entre pensamento e escrita ou, ainda, uma estranheza "que responde, na própria linguagem, a interrupção que introduz a espera" (BLANCHOT, 2010a, p. 134). Assim, pensar, como fez Derrida, uma superação dessa diferença ou, como fez Artaud, a aniquilação da diferença liberada pela linguagem enquanto representação de seu pensamento, seria, de fato, pensar o fim da linguagem. Porque, para que haja linguagem, deve haver interrupção. Dito de outro modo: não haveria linguagem se não fosse para se comunicar com o que me é exterior, com o que me é diferente; portanto, linguagem é diferença, é "palavra não pontificante, capaz de ultrapassar as duas margens, que o abismo separa, sem preenchê-lo e sem reuni-las (sem referência à unidade)" (BLANCHOT, 2010a, p. 135).

Esse lugar e não lugar, visível e invisível, que se estabelece entre o pensamento e a representação na linguagem e que Derrida intitula "poder furtivo", é o que não permite a unificação. Assim, esse espaço neutro é pensado por Blanchot como o lugar anônimo que implica em toda relação, uma vez que não se trata mais do "eu" ou do "ele", mas sim da passagem do "eu" ao "ele", da primeira à terceira pessoa. Ou seja, o "eu" se direciona ao outro, "ele", na intenção de se comunicar, de acessar, de apreender, no entanto, a relação entre ambos, só pode ser fundada na própria interrupção, em uma alteridade em que o outro está totalmente fora de mim e revela "o desconhecido em sua infinita distância" (BLANCHOT, 2010a, p. 134). Então, sendo a linguagem o espaço de experiência do neutro, pois surgiu pela diferença, pode-se falar que, para Blanchot, a linguagem literária é essencialmente o 
lugar de ação do neutro em que o "eu", o sujeito, buscando ao outro, abandona a si e abre-se para o Fora. Ao escrever, esse sujeito busca algo que é externo a si, portanto, fora de si, então sua escrita já não é mais sobre si, é sobre o exterior. É no momento em que o escritor/poeta se coloca a escrever em direção ao outro que é interrompido por uma inapreensão do outro, na qual a obra aparece. Ou seja, a obra é resultado da relação entre o sujeito tentando apreender o outro inapreensível que, na impossibilidade de apreensão, a própria obra surge por uma relação tripla: sujeito/neutro/outro, assim, para Blanchot, é impossível falar sobre a essência da escrita. Desse modo, não há como pensar a literatura a partir da subjetividade de quem escreve, pois no processo de escrita aparece a autonomia da própria obra, a escrita é atravessada pela exterioridade.

Assim, a linguagem literária, para Blanchot, é essencialmente a linguagem do Fora. Sendo a escrita essa relação incessante com o que me é exterior, o que escrevo não é o outro; eu não o apreendo. Assim, é ficção, irrealidade. Nesse sentido, quando Blanchot fala do desaparecimento do autor e aparecimento da obra, como consta em La part du feu, é quando se pode falar de uma experiência do Fora. Se a escrita é desejo metafísico de transcendência em direção ao outro, é porque não se escreve para si, mas se busca exprimir em direção a uma exterioridade, para outros: "é porque não é apenas sua frase, mas a frase de outros homens capaz de lê-la, uma frase universal" (BLANCHOT, 2011a, p. 316). Então, se para Blanchot não há como estabelecer a essência da obra literária/poética, há, no entanto, como reconhecer as relações que a possibilita: "o leitor faz a obra; lendo-a, ele a cria; é seu verdadeiro autor, é a consciência e a substância viva da coisa escrita; assim, o autor tem uma meta, escrever para o leitor e se confundir com ele" (BLANCHOT, 2011a, p.316). O que também não se realiza, pois o leitor busca a obra literária buscando a diferença, o outro, estrangeiro. Então, ao ponto em que entre o "eu" se relaciona com "ele" e é desconhecido ao outro, estabelece-se a experiência com o fora: "quando outrem se revela a mim como o que está absolutamente fora do mundo e acima de mim, não porque seria mais poderoso, mas porque, aí, cessa meu poder, é o rosto" (BLANCHOT, 2010a, p. 102).

A este pensamento de alteridade, Levinas chamou de rosto. Que não é tomado como uma parte do corpo, mas sim como a presença do outro. É a experiência pela qual Blanchot considera que se dá a relação com o externo como im-possibilidade. No momento em que, através do contato da visão, eu ilumino a existência de outro através do meu poder de desvelamento e o outro se mostra inacessível e, por fim, demonstra a minha impotência. É a presença do exterior que se dá na experiência do rosto e que, para Blanchot, não se trata de luz ou ausência de luz, mas sim, que na revelação da existência de outro, na tentativa de transcender, o sujeito fala ao outro. E nessa fala que é palavra, ou seja, um apelo ao outro, que está fora de mim, que é estrangeiro, é o exterior que se manifesta através da palavra. Assim, só há linguagem porque há diferença, sem essa estranheza causada pelo o que o outro é não haveria necessidade de comunicação, partindo do pressuposto de o desejo de transcendência se dá pelo que é o estrangeiro e não mais o "eu", o mesmo. A respeito disso, Blanchot e Levinas consideram a impossibilidade de pensar uma ontologia, pois teorizar o ser só seria possível através do outro enquanto eu mesmo, já que é sempre inacessível.

DIONIZIO, Mayara Joice. Unidade ou diferença: entre o corpo derridiano e a poesia blanchotiana. Griot : Revista de Filosofia, Amargosa - BA, v.19, n.2, p.154-170, junho, 2019. 
Nessa relação, o homem é o que existe como mais distante do homem, o que permite a Blanchot dizer:

\begin{abstract}
Por isto, se a metafísica é a relação transcendente com outrem, como esta transcendência é primeiramente de ordem moral - medida por uma impossibilidade que é uma proibição -, é preciso então dizer que a filosofia primeira não é a ontologia, a preocupação, a questão ou apelo do Ser, mas a ética em relação a outrem (BLANCHOT, 2010a, p. 102).
\end{abstract}

Portanto, se há linguagem, ainda que inapreensível do outro, é na necessidade de se criar um elo, e a partir disso, cria-se um ethos através da responsabilidade que sentimos pelo outro a partir da separação. Para Blanchot, o ser sempre foi pensado a partir do eu mesmo, ao menos no sentido de reconhecer no outro o eu, mas nunca do outro como inacessível. E, disso, dessa recusa ocidental do neutro, da impossibilidade, que se pensou o ser como Uno, unidade que mantém o pensamento sobre seu domínio.

O sofrimento de Artaud é por uma crença nesse domínio. Dessa forma, tanto o conceito de unidade quanto o de diferença pensados por Blanchot em relação à escrita, de outra maneira do que a pensada por Derrida, constituem-se a partir da experiência com o outro porque é no intervalo entre o "eu" e o "ele" que se revela a diferença e a impossibilidade de unidade. Artaud, nesse sentido, escreveu sobre essa impossibilidade frente ao outro relatando como isso se mostrava a partir da tentativa poética, e, mesmo que buscando superar esse intervalo, "não podia, sem fraude, permitir que lhe fosse retirada sua 'impotência', que era o ponto de partida de sua protestação, nem sua solidão, sem a qual não poderia haver para ele comunicação" (BLANCHOT, 2010b, p. 183). Assim, Blanchot reconhece que as recusas de Artaud, como o surrealismo, por exemplo, que reuniu linguagens distintas e configurou-se quase totalmente a pensar a linguagem, foi pela afirmação surrealista da diferença, justamente porque o desconhecido é plural. Porque, para Blanchot, o surrealismo tratou muito mais de uma "exigência de uma pluralidade que escapa à unificação, excedendo o todo (ao mesmo tempo que o supõe e reclama-lhe a realização) e mantendo, diante do Único, incansavelmente a contradição e a ruptura" (BLANCHOT, 2010b, p. 182). Pode-se, então, perceber que Artaud atingiu a profundidade de descrição da impotência em relação à escrita e de uma forma quase ingênua, afirmando, por outra via, não o Único, mas a diferença.

Blanchot sempre reconheceu na obra artaudiana o limite que ali era denunciado como insuperável; já Derrida reconheceu em tal limite a possibilidade de transgressão. Blanchot diz, ao fim de "La cruelle raison poétique", a propósito de seu comentário sobre Artaud: "por fim, aquilo que ele temia - que a loucura, o grito, a fala imediatamente dispersada não fossem mais do que elementos de uma estratégia - é o que ocorre, e justamente a seu propósito (e já nesse texto também)" (BLANCHOT, 2010b, p. 27). Ou seja, Blanchot sabe de seu reducionismo em relação ao que pretendia Artaud (acabar com a diferença), nesse ponto, assemelha-se a Rivière, ambos reconheceram o valor de Artaud pela fala de impossibilidade de realização poética. Portanto, para Blanchot, Artaud percebia na impossibilidade o rigor extremo, ao ponto que a intitula cruel porque traz diferença, nunca deixa exprimir o pensamento e, assim, mesmo com o teatro, não se alcança uma expressão.

DIONIZIO, Mayara Joice. Unidade ou diferença: entre o corpo derridiano e a poesia blanchotiana. Griot : Revista de Filosofia, Amargosa - BA, v.19, n.2, p.154-170, junho, 2019. 
Por fim, sua impossibilidade era seu desejo e seu desejo era impossibilidade. Desse modo, pensar a impotência de Artaud como fez Derrida, levando a linguagem ao limite para se reconhecer o limite, é uma forma de reconhecer na experiência artaudiana o valor da impotência comum à linguagem, mas, ainda assim, singularizando-a. Se a estrutura da linguagem é furtiva ou permite o furto e todo ato de criação poética é atravessado pelo instante da impossibilidade, o que se deve reconhecer em Artaud é a descrição dessa impossibilidade. Dito de outra forma: Derrida fala a partir de Artaud sobre o sopro, sobre o roubo que se dá nesse ato, percebe-se que o outro aí tem lugar central. Ou seja, o sopro só existe em vistas do outro, soprar, escrever, falar para alguém; então, ao escrever, Artaud sabe que sua impossibilidade é o outro, e isso se configura sempre em uma revolta contra o outro, porque o que lhe é exterior não lhe permite ser inteiro: Deus, o público, a poesia, o teatro, a metáfora. Se Derrida reconhece em Artaud uma experiência crítica da diferença com o objetivo de uma transgressão da metafísica, então sua leitura, apesar de problematizar a diferença com vistas à unidade, vale-se da obra de Artaud pela possibilidade de afirmar "a lei cruel (isto é, no sentido em que entende esta última palavra, necessária) da diferença; lei desta vez levada à consciência" (DERRIDA, 2011, p. 287). Ou seja, o furto derridiano, nos próprios termos de Derrida, é muito maior. Não se trata mais somente do roubo do comentário, mas, sim, do uso que é feito de Artaud para além de Artaud. Derrida se refere a Blanchot como reducionista de uma unidade em prol de uma essência. No entanto, pode-se ver em Derrida, mesmo com vistas à unidade, um reducionismo de Artaud em prol de uma metafísica e, nesse sentido, a violência do comentário, do furto.

Vê-se que Derrida assumiu, por meio de Artaud, a possibilidade de se efetivar uma superação e Blanchot, uma descrição do espaço literário enquanto experiência limite, segundo a qual pode-se falar que Artaud deu lugar ao combate entre pensar e escrever e aceitou ser o espaço de precisão em relação ao impossível. E, nesse sentido, Blanchot compreendeu que a impossibilidade era a paixão artaudiana, como de todo autor que experiencia na escrita a presença da exterioridade e se dedica a buscá-la incessantemente. Todas as tentativas de Artaud em relação à linguagem confluem sobre o outro, o exterior, o Fora, ao ponto em que a maior problematização se torna a representação na linguagem e, posteriormente, no teatro, por uma renovação da linguagem, a fim de acabar com a interrupção, com a fissura. Se a problematização de Artaud sobre a separação, a dicotomia, sempre ocorreu no campo da linguagem e todas suas tentativas foram de superá-la enquanto falta, é certo afirmar que sempre se tratou de um problema suscitado pela poesia e permaneceu essencialmente poético. Nesse sentido, o corpo só se torna um problema em relação ao espírito, porque decorre da percepção da falta primeira: a de pensar e de escrever. 


\section{Referências:}

ARTAUD, Antonin. O Teatro e seu Duplo. Tradução de Teixeira Coelho. São Paulo: Companhia das letras, 2006.

ARTAUD, Antonin. Oeuvres. Apresentação e notas de Évelyne Grossman. Paris: Quarto Gallimard, 2004.

BLANCHOT, Maurice. A parte do fogo. Tradução de Ana Maria Scherer. Rio de Janeiro: Ed. Rocco, 2011a.

BLANCHOT, Maurice. Conversa Infinita, a - Vol.1- A palavra plural. Tradução de Aurélio Guerra Neto. São Paulo: Editora Escuta, 2010a.

BLANCHOT, Maurice. Conversa Infinita, a - Vol.2- A experiência limite. Tradução de João Moura Jr. São Paulo: Editora Escuta, 2007.

BLANCHOT, Maurice. Conversa Infinita, a - Vol. 3 - A ausência de Livro. Tradução de João Moura Jr. São Paulo: Editora Escuta, 2010b.

BLANCHOT, Maurice. O espaço literário. Tradução de Álvaro Cabral. Rio de Janeiro: Ed. Rocco, 2011b.

BLANCHOT, Maurice. O Livro por Vir. Tradução de Leyla Perrone-Moisés. São Paulo: Matins Fontes, 2013.

CARVALHO, MARIA. Entre Filosofia e Literatura: geometrias de uma relação em Maurice Blanchot e Paul Ricoeur. Centro de Literaturas e Culturas Lusófonas e Europeias, Faculdade de Letras da Universidade de Lisboa Lisboa, agosto de 2014.

DERRIDA, Jacques. Escritura e Diferença. Tradução de Maria Beatriz Marques Nizza da Silva. São Paulo: Editora Perspectiva, 2011.

DERRIDA, Jacques. Marges de la Philosophie. Les Editions de Minuit. Paris,1972. PLATÃO. O Banquete. São Paulo: Editora 34, 2016.

Autor(a) para correspondência: Mayara Joice Dionizio, Universidade Federal do Paraná, Departamento de Filosofia, Rua Dr. Faivre, $4036^{\circ}$ Andar Ed. D. Pedro I, Centro, 33605-98, Curitiba - PR, Brasil.mayaradioniso@hotmail.com 